American J. of Engineering and Applied Sciences 1(1): 53-56, 2008

ISSN 1941-7020

(C) 2008 Science Publications

\title{
Synthesis and Charaterization of Magnesium Zinc Ferrites as Electromagnetic Source
}

\author{
${ }^{1}$ Noorhana Yahya, ${ }^{1}$ Ami Salwani Mohamad Nor Aripin, ${ }^{1}$ Azizuddin A. Aziz, ${ }^{1}$ Hanita Daud, ${ }^{1}$ Hasnah \\ Mohd Zaid, Lim Kean Pah and ${ }^{2}$ Norehan Maarof \\ ${ }^{1}$ Department of Electrical and Electronic Engineering,Universiti Teknologi \\ PETRONAS, Bandar Seri Iskandar, 31750 Tronoh, Perak, Malaysia \\ ${ }^{2}$ Department of Physics, Faculty of Science, Universti Putra Malaysia \\ 45400 UPM Serdang, Selangor
}

\begin{abstract}
Fabrication of $\mathrm{Mg}_{1-\mathrm{x}} \mathrm{Zn}_{\mathrm{X}} \mathrm{Fe}_{2} \mathrm{O}_{4}$ (where $\mathrm{x}=0.2,0.3,0.4$ and 0.5 ) samples using a conventional technique is reported. Oxides of magnesium, zinc and iron with purity of about $99.99 \%$ were mixed with distilled water in a milling machine for 12 hours. They were then filtered and presintered at $1250^{\circ} \mathrm{C}$ and sintered at $1350^{\circ} \mathrm{C}$ for $10 \mathrm{~h}$ in air. The phase and the crystal structure of the asprepared samples were identified using X-Ray Diffraction analysis (XRD). Hysteresis graph was evaluated using Vibrating Sample Magnetometer (VSM) to get the saturation magnetization (emu g ${ }^{-1}$ ) and coercivity (G) value. Atomic Force Microscope (AFM) was used to observe the surface morphology. The X-ray diffraction analysis showed major peak at plane $\left(\begin{array}{lll}3 & 1 & 1\end{array}\right)$ of the cubic structure for all the ferrites. The largest value of density achieved was $4.69 \mathrm{gcm}^{-3}$ which was exhibited by sample with 0.5 mole fraction of zinc content. Highest saturation magnetization value $\left(3.652 \mathrm{emu} \mathrm{g}^{-1}\right)$ was obtained for the 0.3 mole fraction of zinc content. A strong correlation between the saturation magnetization and zinc content was observed. We speculate that it is due to the Heisenberg superexchange interaction of magnetic $\mathrm{Fe}^{3+}$ and non-magnetic $\mathrm{Zn}^{2+}$ occupying the tetrahedral sites. The sample was used to induce electromagnetic (EM) waves in high operating frequency $(5 \mathrm{MHz})$.
\end{abstract}

Key words: Tetrahedron, x-ray diffraction, hysteresis, electromagnetic field and super-exchange interaction

\section{INTRODUCTION}

Soft magnetic material has been used widely in many electronic devices. The most popular type is the cubic spinel structure which has tetrahedral A site and octahedral $\mathrm{B}$ site in the $\mathrm{AB}_{2} \mathrm{O}_{4}$ crystal structure ${ }^{[1]}$. It is because their magnetic properties are easy to control as it depends regularly on the variation of the compositions and cation distribution. Moreover it often has high permeability in the Radio-Frequency (RF) region, high electrical resistivity, mechanical hardness, chemical stability and reasonable cost ${ }^{[2]}$. Zinc is known as the main contributor in determining the ferrite properties. It was proven that variations in zinc content is able to tune the resonance frequency ${ }^{[3]}$. In fact, the application of ferrite as a magnetic feeder to excite an antenna that can cover wide frequency bandwidth from $200 \mathrm{MHz}-1 \mathrm{~Hz}$ with different length $0.3-50 \mathrm{~m}^{[4]}$ was reported. Ferrites containing $\mathrm{Mg}$ and $\mathrm{Zn}$ possess higher resistivity value than $\mathrm{Mn}-\mathrm{Zn}$ one $\left(\sim 10^{7} \Omega \mathrm{cm}^{-1}\right)$ where the resistivity of $\mathrm{Mg}-\mathrm{Zn}$ ferrite is $10^{6}-10^{7} \Omega \mathrm{cm}^{-1}$ and make it more effective in high frequency ${ }^{[5]}$. It was found that the sintering temperature has strong effect on the microstructure and as such may affect the hysteresis ${ }^{[6]}$. This study premise deals with fabrication and characterization of magnesium zinc ferrite, $\mathrm{Mg}_{1}$ ${ }_{x} Z_{X} F_{2} \mathrm{O}_{4} \quad(0.2 \leq x \leq 0.5)$ samples using conventional solid state reaction. A high saturation magnetization is expected to be seen. The enhancement of the study will be proceeding on the application of the as-prepared sample to be used as an Electro Magnetic (EM) source. This study premise shall be the basis of us using the EM source in hydrocarbon detection for onshore exploration.

Experimental: The raw materials consist of $\mathrm{MgO}, \mathrm{ZnO}$ and $\mathrm{Fe}_{2} \mathrm{O}_{3}$ according to their weight ratio were mixed with the distilled water in a milling machine for $24 \mathrm{~h}$. The added distilled water led the mixing process and helped the fluid cooling before the mixture was filtered

Corresponding author: Noorhana Yahya, Department of Electrical and Electronic Engineering, Universiti Teknologi PETRONAS, Perak, Malaysia. 
and dried in an oven at $110^{\circ} \mathrm{C}$ for $24 \mathrm{~h}$. After that the pre-sintering process were done in the carbolite furnace at $1250^{\circ} \mathrm{C}$ for $10 \mathrm{~h}$. During the pre-sintering process, the mixtures combine by the solid-state reaction where the atoms get into the lattice to form the crystal structure. The pre-sintering process also allows the decomposing of the oxides to avoid formation of unwanted gaseous. It evaporates the unknown masses that remain in the samples. Then the materials are crushed by using porcelain mortar until finer texture is observed and the grinding process will take place in about 6 hours by using Fritisch Planetary Micromill. Next, the mixture was dried in the oven at $110^{\circ} \mathrm{C}$ for 24 $\mathrm{h}$. The sample was crushed again and added with $1 \mathrm{wt} \%$ of Polyvinyl Alcohol (PVA) to act as a binder and 1 $\mathrm{wt} \%$ of zinc stearate to fill the pores between the particles to give better reaction during sintering. The rate of the grain growth depends on the sintering temperature, the stoichiometry and the oxygen partial pressure ${ }^{[7]}$. The sintering process was done at $1350^{\circ} \mathrm{C}$ for $10 \mathrm{~h}$. in air. The heating permits the mobility of the atoms for the grain growth. Thus at this stage a spinel lattice is expected to be formed. The characterization of the sintered samples was done by Philips X-ray diffractometer to confirm the formation of the single phase cubic spinel crystal structure, Lakeshore-7300 Vibrating Sample Magnetometer (VSM) to evaluate the saturation magnetization and Atomic Force Miscroscope for surface morphology observation. Small MgZn Ferrite toroid core with 120 turns was used to produce EM field. GW INSPEK GFG-8250A function generator was used to induce a $5 \mathrm{MHz}$ sinusoidal wave. The peak to peak Voltage was detected using a Tektronix digital oscilloscope TDS 3012B.

\section{RESULTS AND DISCUSSION}

The density of the samples was evaluated by using the Archimedes principle. It shows the densities increased from $3.34 \mathrm{gcm}^{-3}$ to $4.69 \mathrm{gcm}^{-3}$ by increasing the $\mathrm{Zn}$ content in sample. The values are in agreement with the literature data that is in between $4.520 \mathrm{gcm}^{-3[8]}$. Zinc is known to bring about the densification, grain growth and reduce anisotropy ${ }^{[4]}$.

The X-Ray Diffraction (XRD) measurements were carried out using $\mathrm{Cu} \mathrm{K}$ radiation $(\lambda=0.54 \mathrm{~nm})$ with a Philips diffractometer (PW1830/3210) operated at $35 \mathrm{kV}$ and $25 \mathrm{~mA}$ in the range of $22-80^{\circ}$ of the $2 \theta\left(^{\circ}\right)$.

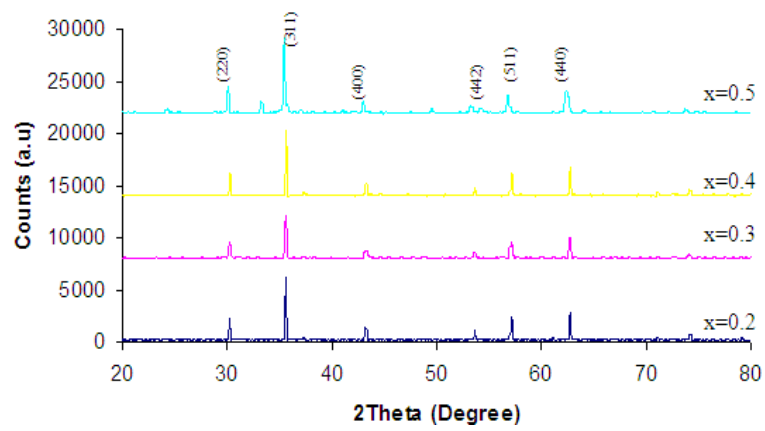

Fig. 1: XRD Pattern After Sintering at $1350^{\circ} \mathrm{C}$ for $\mathrm{Mg}_{1-}$ ${ }_{\mathrm{X}} \mathrm{Zn}_{\mathrm{X}} \mathrm{Fe}_{2} \mathrm{O}_{4}$ samples

Table 1: Values of density, d-spacing $(\AA)$, intensity after presintering and after sintering at plane $\left(\begin{array}{lll}3 & 1 & 1\end{array}\right)$ for $\mathrm{Mg}_{1-\mathrm{X}} \mathrm{Zn}_{\mathrm{X}} \mathrm{Fe}_{2} \mathrm{O}_{4}$ samples

\begin{tabular}{lllll}
\hline $\mathrm{X}(\mathrm{mol})$ & $\begin{array}{l}\text { Density, } \rho \\
\left(\mathrm{gcm}^{-3}\right)\end{array}$ & $\begin{array}{l}\text { d-spacing } \\
(\AA)\end{array}$ & $\begin{array}{l}\text { Intensity After } \\
\text { presintering } \\
\text { (counts) }\end{array}$ & $\begin{array}{l}\text { Intensity After } \\
\text { sintering } \\
\text { (counts) }\end{array}$ \\
\hline 0.2 & 3.34 & 2.5195 & 4322 & 5418 \\
0.3 & 3.82 & 2.5193 & 4070 & 6203 \\
0.4 & 4.68 & 2.5159 & 6165 & 6355 \\
0.5 & 4.69 & 2.5338 & 4767 & 5308 \\
\hline
\end{tabular}

All of the lines in the pattern were indexed by cell refinement with a cubic structure of space group $\mathrm{Fd}-3 \mathrm{~m}$ (SG\#227). The XRD patterns of $\mathrm{Mg}_{1-\mathrm{X}} \mathrm{Zn}_{\mathrm{X}} \mathrm{Fe}_{2} \mathrm{O}_{4}$ ferrites after sintering at $1350^{\circ} \mathrm{C}$ are shown in Fig. 1, indicating a single phase cubic spinel structure (JCPDS card number 00-008-0234) where the diffraction spots at d-spacing values of $2.5195 \AA, 2.5193 \AA, 2.5159 \AA$ and $2.5338 \AA$ for $\left(\begin{array}{lll}3 & 1 & 1\end{array}\right)$ plane reflection as the major peaks. A well-crystalline single phase structure were described by the intense sharp peak of the diffraction pattern as well as there were almost no second phases formed in the samples when temperature was increased to $1350^{\circ} \mathrm{C}$. The sintering process had cause the atom to move to its lattice completely. In fact it is understood that the $\mathrm{Zn}^{2+}$ ions occupy the tetrahedral (A) site, $\mathrm{Mg}^{2+}$ ions have a preference for the octahedral (B) site while the $\mathrm{Fe}^{3+}$ ions are distributed over both site ${ }^{[9]}$. From Table 1, we can observe that the diffracted intensity of all the sintered samples is higher than those of presintering samples.

Hysteresis loops (Fig. 2) are observed for the measurement of saturation magnetization $\left(\mathrm{emu} \mathrm{g}^{-1}\right)$ and coercivity (Gauss) that is a result of several intrinsic and extrinsic properties which depends on some factors such as density, anisotropy, grain size and A-B exchange interactions ${ }^{[4]}$. As can be seen from the graph and the table, the $\mathrm{Mg}-\mathrm{Zn}$ ferrite obtained in this project showed a normal type (S-shape) hysteresis curve with high saturation magnetization and narrow loop that brought the low coercivity values ranging from 0.371 $1.023 \mathrm{G}$. 


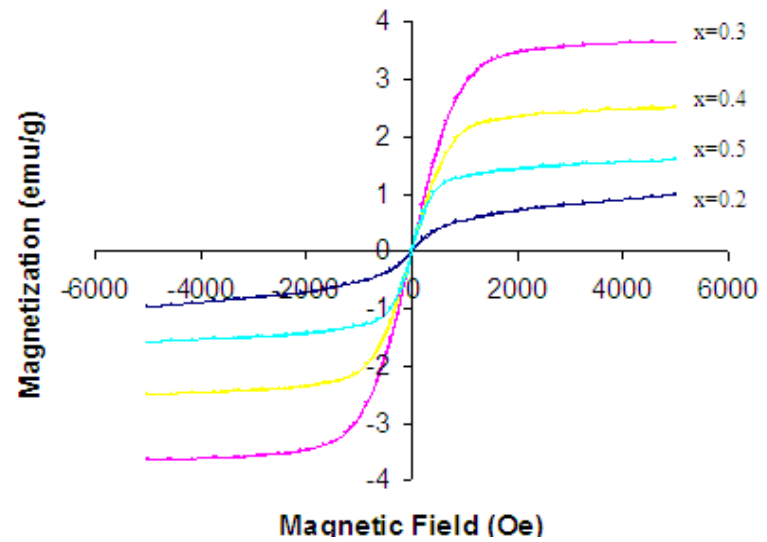

Fig. 2: Hysteresis for $\mathrm{Mg}_{1-\mathrm{X}} \mathrm{Zn}_{\mathrm{X}} \mathrm{Fe}_{2} \mathrm{O}_{4}$ samples

Table 2: Value of Saturation Magnetization, Coercivity and Average Particle Size of $\mathrm{Mg}_{\mathrm{x}} \mathrm{Zn}_{1-\mathrm{x}} \mathrm{Fe}_{2} \mathrm{O}_{4}$ samples

\begin{tabular}{|c|c|c|c|}
\hline $\begin{array}{l}\mathrm{X} \\
\text { (mole fraction) }\end{array}$ & $\begin{array}{l}\text { Saturation } \\
\text { Magnetization, } \\
\mathrm{M}_{\mathrm{s}}\left(\mathrm{emu} \mathrm{g}^{-1}\right)\end{array}$ & $\begin{array}{l}\text { Coercivity } \\
\text { (Gauss) }\end{array}$ & $\begin{array}{l}\text { Average Particle } \\
\text { Size, } \mu \mathrm{m}\end{array}$ \\
\hline 0.2 & 0.974 & 1.023 & 1.94 \\
\hline 0.3 & 3.652 & 0.889 & 1.48 \\
\hline 0.4 & 2.508 & 0.548 & 1.40 \\
\hline 0.5 & 1.598 & 0.371 & 1.64 \\
\hline
\end{tabular}

The saturation magnetization increases from 0.974$3.652 \mathrm{emu} \mathrm{g}^{-1}$ and then decreasing to 2.508 and 1.598 emu $\mathrm{g}^{-1}$. The saturation magnetization value supposed to increase by substituting the zinc content. Instead, Ms shows a decreasing trend when $\mathrm{x}=0.4$. This phenomenon can be explained further. $\mathrm{MgZnFe}_{2} \mathrm{O}_{4}$ has inverted spinel crystal structure ${ }^{[1]}$. It is known that $\mathrm{Zn}^{2+}$ ion prefer tetrahedral (A-sites), $\mathrm{Mg}^{2+}$ ion prefer octahedral(B-sites) while $\mathrm{Fe}^{3+}$ ion distributed over both sites. The preference of the non-magnetic $\mathrm{Zn}^{2+}$ ion in the A-site will encourage the migration of $\mathrm{Fe}^{3+}$ ion into B-site which gives rise to antiparallel spin coupling and spin canting resulting in weakening of the A-B exchange interaction thus increase the saturation magnetization ${ }^{[3]}$. However, with more and more $\mathrm{Zn}^{2+}$ ion, the $(x>0.4-0.5)$ the ferrite become normal spinel. The A-B super-exchange interaction weakens and this will result stronger B-B interaction. Due to this, magnetic moments of a part of $\mathrm{Fe}^{3+}$ ions (which are now only in B-position) becomes reversibly oriented which leads to the decrease of the total magnetic moment in ferrites ${ }^{[1]}$.

Microstructure analysis: As can be seen from the Fig. 3 , the surface morphology of the samples is rough. It is nonhomogeneous microstructure because the average particle size for every sample is different. Each particle usually contained a large number of atoms. From
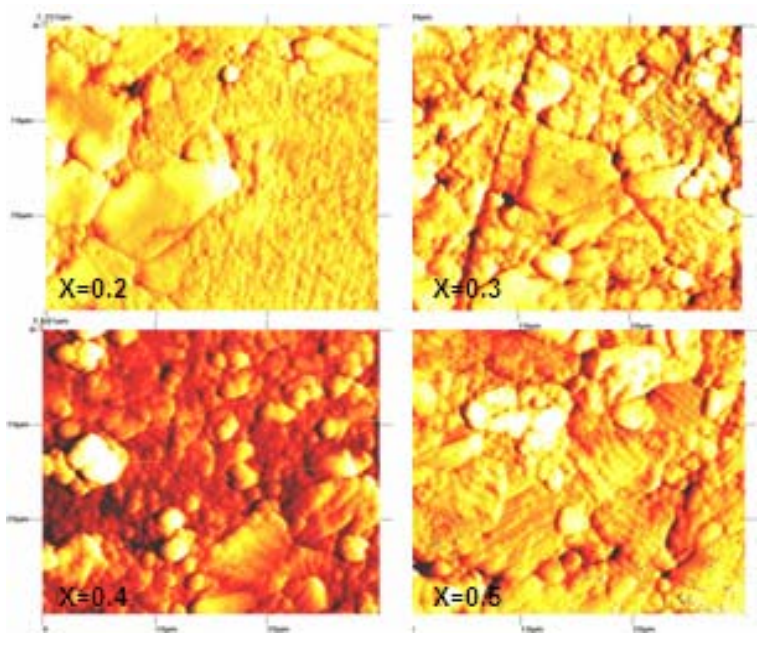

Fig. 3: The morphology of $\mathrm{Mg}_{1-\mathrm{x}} \mathrm{Zn}_{\mathrm{x}} \mathrm{Fe}_{2} \mathrm{O}_{4}$ samples where $\mathrm{X}=0.20 .3,0.4$ and 0.5 after sintering at $1350^{\circ} \mathrm{C}$.

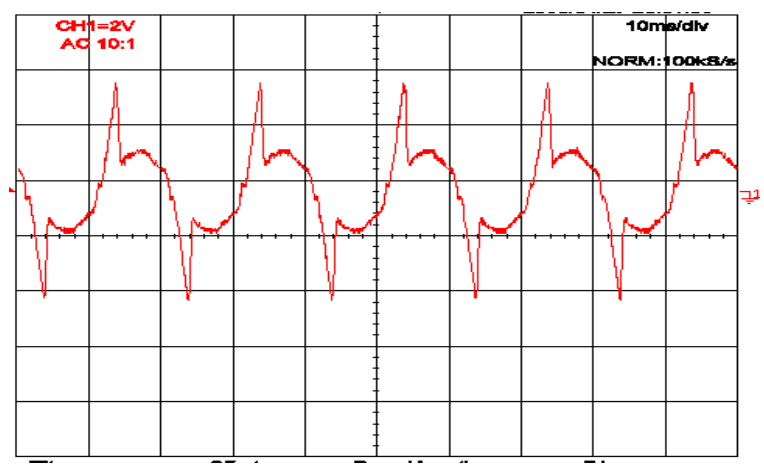

Fig. 4: Voltage versus time of the MgZnFerrite based EM source

Table 2, we can see that 0.2 mole fraction zinc content has the largest average particle size.

The ferrite sample was used to induce electromagnetic field at $5 \mathrm{MHz}$. The voltage (peak to peak) obtained was about $12.8 \mathrm{~V}$ (Fig. 4). The toroidal shape EM source were able to transmit EM wave to more than 1 meter. It should be noted that an induction coil EM detector was used to detect the EM waves. Traces of the hysteresis behavior can be seen on the graph plot. More work on the EM source system shall be carried out in our lab.

\section{REFERENCES}

1. Kong, F.N., 2004. Excitation of a long wire antenna-Antenna from $200 \mathrm{MHz}$ to $1 \mathrm{~Hz}$. In: 10th International Conference on Ground Penetrating Radar. 
2. ZbigniewPe, Dzich, 2004. Microstructure and properties of $\mathrm{Mg}-\mathrm{Zn}$ ferrite as a result of sintering temperature. J. Eur. Ceramic Soc., 24: 1053-1056.

3. Khedr, M.H., 2006. Effect of firing temperature on microstructure and magnetic properties of nanocrystalline $\mathrm{Ni}_{0.5} \mathrm{Zn}_{0.5} \mathrm{Fe}_{2} \mathrm{O}_{4}$ prepared by wet and dry method. J. Analytical and Applied Pyrolysis., 76: 203-208.

4. Wen-Hsi Lee, 2001. Effects of ceramic processing parameters on the microstructure and dielectric properties of $\left(\mathrm{Ba}_{1-\mathrm{x}} \mathrm{Ca}_{\mathrm{x}}\right)\left(\mathrm{Ti}_{0.99-\mathrm{y}}, \mathrm{Zr}_{\mathrm{y}} \mathrm{Mn}_{0.01}\right) \mathrm{O}_{3}$ sintered in a reducing atmosphere. J. Mater. Sci. Mater. Electronics, 12: 123-130.
5. Skołyszewska, B., 2003. Preparation and magnetic properties of MgZn and MnZn ferrites. Physica C, 387: 290-294.

6. Souilah Zahi, 2006. Preparation of Ni-Zn-Cu ferrite particles by sol-gel technique. J. Magnetism Magn. Mater., 60: 2803-2806. 